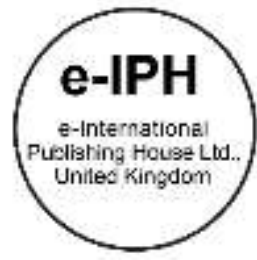

\title{
Healthcare Internationalisation: An analysis of the behaviour of medical practitioners towards local patients
}

\author{
Nuraisyah Chua Abdullah¹, Herwina Rosnan², Norzayana Yusof ${ }^{3}$ \\ ${ }^{1}$ Faculty of Law, \\ 2Arshad Ayub Graduate Business School, \\ ${ }^{3}$ Centre for Postgraduate and Professional Studies, Faculty of Business and Administration, \\ Universiti Teknologi MARA, Shah Alam, 40450. Selangor. Malaysia
}

nuraisyahc@yahoo.com; nuraisyah@salam.uitm.edu.my; herwinaros@gmail.com; norzayana.yusof@yahoo.com Tel: +6019-6488348

\begin{abstract}
Malaysia is among the chosen countries for medical tourism due to its excellent healthcare services. Nevertheless, there are concerns if service providers are balancing the local and foreign patient's demands. Due to the lack of discussion on medical practitioners' behaviour towards local patients, this paper aims to analyse the similarities and differences of their behaviour on these two groups. Through literature analysis, it is found that unhealthy behaviour towards local patients is profound. Hence, the discussions are hoped to spark the policy-makers' attention in restructuring the healthcare policy to realign the medical practitioners' behaviour on both patient groups.
\end{abstract}

Keywords:Medical Tourism; Healthcare Internationalisation; Medical Practitioners' Behaviour; Local Patients

eISSN: 2398-4287@ 2018. The Authors. Published for AMER ABRA cE-Bsby e-International Publishing House, Ltd., UK. This is an open access article under the CC BYNC-ND license (http://creativecommons.org/licenses/by-nc-nd/4.0/). Peer-review under responsibility of AMER (Association of Malaysian Environment-Behaviour Researchers), ABRA (Association of Behavioural Researchers on Asians) and cE-Bs (Centre for Environment-Behaviour Studies), Faculty of Architecture, Planning \& Surveying, Universiti Teknologi MARA, Malaysia.

DOI: https://doi.org/10.21834/e-bpj.v3i8.1389

\subsection{Introduction}

While cultural heritage stands as one of the focal points of leisure tourism (Azmi \& Ismail, 2016) the escalating trend of consumption and provision of healthcare services across country borders over the past decades is on the rise (Lunt et al., 2011). 'Medical tourism' finds its prominent antecedents from the movement of patients from one country to another, in search of medical and health treatments. While the procedure may cover a wide range of medical services, the most common includes fertility treatment, elective surgery, dental care and cosmetic surgery(Nisha, 2017). The major pushing factors that thrust medical travellers to other countries are the flaws in the healthcare services in their home country namely expensive healthcare costs and the long waiting list. Accordingly, many developing governments are headed towards utilising their advantages in medical tourism, while asserting that revenue earned and foreign exchange can be converted to subsidise the treatment of poor patients. Hence, marketing of medical tourism is perceived as a tool to accomplish the mandate of social justice and promote health equity (Gola, 2015).

Notwithstanding the massive media coverage, there is a lack research evidence on the role and impact of medical tourism for countries of service providers (Lunt et al., 2011). Specifically, studies on the behaviour of medical practitioners towards the local and foreign patients that undergo the medical tourism are scarce. While medical tourism possesses an array of employee risks and opportunities for patients, there are concerns that the behaviour of healthcare employees is inconsistent between the local and foreign patients. In Thailand and India, this problem occurs in various forms such as internal brain drain as doctors tend to leave public and

eISSN: 2398-4287@ 2018. The Authors. Published for AMER ABRA cE-Bsby e-International Publishing House, Ltd., UK. This is an open access article under the CC BYNC-ND license (http://creativecommons.org/licenses/by-nc-nd/4.0/). Peer-review under responsibility of AMER (Association of Malaysian Environment-Behaviour Researchers), ABRA (Association of Behavioural Researchers on Asians) and cE-Bs (Centre for Environment-Behaviour Studies), Faculty of Architecture, Planning \& Surveying, Universiti Teknologi MARA, Malaysia.

DOI: https://doi.org/10.21834/e-bpj.v3i8.1389 
rural hospitals to take up the lucrative opportunities offered by private hospitals that serve for medical tourists (Chen \& Flood, 2013). This leads towards the healthcare practitioners neglecting the local patients especially the poor or those in rural areas to utilise the capacities in serving for the medical tourists (Helble, 2011). Similarly, Malaysia is facing problems on the availability of healthcare services and specialists particularly in rural areas (Razak, 2015). Although the establishment of Klinik 1 Malaysia (K1M) has been widely accessed by the public through its 360 branches that has catered for 6.47 millions of patients in 2016 (National Transformation Program, 2017), the K1Ms are mainly available in urban areas leaving the gap of healthcare accessibility and affordability to the locals in rural areas. Moreover, there is no empirical evidence to prove the 'trickling down' of any material benefit to the poor resulting from opening up the healthcare sector to privatisation and internationalisation (Gola, 2015).

Hence, the present paper aims to elaborate on the existing and imminent implications of the practice of medical tourism in the country of service providers on local patients, focusing on the behaviour of the medical practitioners in this industry. In particular, this paper focuses on examining the similarities and differences in the medical practitioners' behaviour towards the local patients vis-à-vis the medical tourists and draw a 'gap' between these two market groups. Thus, this effort is deemed essential in safeguarding health and provision of healthcare services. This is an essential feature of a nation that serves the interest of the locals. With the trend of healthcare services transforming from social good to premium tradable commodity (Gola, 2015), it is of the people's utmost importance to have their rights for welfare protected.

\subsection{Literature Review}

Having described the issue and problems in the medical tourism industry, the present section will elaborate on the needs of ensuring the medical practitioners' equal behaviour between medical tourists and the local patients. This will then be followed by an understanding of internationalisation activities in the healthcare industry.

\subsection{Health and Disparities}

Health is a multi-level construct that includes psychosocial and physical aspects that vary in diverse contexts (Gola, 2015). As opposed to a biomedical definition of health as absence of diseases or abnormalities (Gola, 2015), the World Health Organisation (WHO), through the WHO Constitution, defines health as 'a state of complete physical, mental and social well-being, and not merely the absence of diseases or infirmity' (World Health Organisation, 1946). Further, the Constitution also outlines that the fullest attainment of health is when the benefits of health is being extended to all people regardless of race, gender, social and economic condition, as the improvement of health of the people revolves around informed decision and active co-operation from the public (World Health Organisation, 1946). This signifies the importance of local patients receiving equal treatments by medical practitioners regardless of their nationality and physical and fiscal attributes. The earnings gained from medical tourism industry are supposed to generate opportunities to improve the quality and access of healthcare to the local citizens, through appropriate implementation of policies. Otherwise, the disparity in the healthcare industry, which will be further elaborated in the paper, may impose pervasive effects on the local population's healthcare. Similar to other tourism, provision of appropriate healthcare facilities to the locals are equally essential to the tourists (Fachrudin \& Lubis, 2016).

\subsection{Healthcare sector in Malaysia}

The healthcare sector in Malaysia found its antecedents even before the Independence when hospitals were initially built to serve for the mining workers. In light of the increase communicable diseases, poverty and low health care awareness, more medical institutions were created to improve the living standards of the people. Nevertheless, the formerly 'welfare-oriented' services transformed into the money-making industry as the 1980s privatisation mushroomed (Rasiah, Wan Abdullah, \& Tumin, 2011). Further, Rasiah et al. (2011) also explained that a blend of falling assets and brain drain going up against public hospitals, with an extending supply of private healthcare suppliers clarifying the expanding shift toward private medicinal services in Malaysia. The growth of healthcare provisions indicates that Malaysia practices a mixed healthcare system which consists of public and private healthcare (Rasiah et al., 2011).

\subsection{Healthcare Internationalisation: Past and Present}

Lunt et al. (2011) posited that the consumption of health care in a foreign land is not a new phenomenon, and developments must be situated within the past context. Accordingly, individuals travelled abroad for health benefits since ancient times, and during the 19th Century in Europe for example, the middle-classes travelling to spa towns to take the waters, which were thought to have healthenhancing qualities. Meanwhile, in the 20th Century, wealthy people from less developed areas of the world travelled to developed nations to undergo medical treatments through better facilities and highly trained medical practitioners. However, the shifts that are currently underway concerning medical tourism varied from ancient forms of health-related travel. The fundamental differences are a reversal of this flow from developed to less developed nations, more regional movements, and the emergence of an international market for patients(Lunt et al., 2011).

Medical tourism in Malaysia find its roots back in 1997 during the global financial crisis which had led to local patients opted for public healthcare institutions that offered services for free or at little cost. This happened due to their low purchasing power which resulted in decreased revenues in private healthcare institutions. Further, the fall of Malaysian currency and the Thai baht resulted in rising drugs and medical equipment prices. To counteract, private hospitals resorted to foreign patients to undergo medical treatments in Malaysia through a term called 'medical tourism'. After twenty years, Malaysia's medical tourism industry today has portrayed upward 
achievements especially in the number of international tourists. Malaysia had received over 900,000 foreign medical tourists in 2016 alone which brought revenues of RM1.15 billion to the country (Nisha, 2017).

\subsection{Methodology}

Improvement of the healthcare quality in public and private hospitals is emphasised in the health system goals (Nisha, 2017)which this paper is found to be corresponding with. This paper focuses on the behaviour of medical practitioners in the medical tourism industry towards the local patients and medical tourists and how could improvements be made. The area is chosen due to its lack of research in previous conferences on human behaviour about medical practitioners and let alone in the relatively-young medical tourism industry. Hence, discussions are presented in the form of critical analysis from past and present research. Information is derived from government reports and conceptual and primary data articles. Nevertheless, it is realised that the present paper lacks primary data which calls for future research to validate the presented arguments through empirical research.

\subsection{Discussion}

It is delineated that the problem of medical practitioners' unequal behaviour towards the local patients is apparent. This happens in terms of their tendency to work at internationalised private healthcare institutions that cater for medical tourists due to the lucrative pays offered to them. Consequently, this results in scarcity of healthcare services and specialists in public healthcare especially at rural areas. Therefore, the present article wishes to elaborate on an internationalisation model by Cavusgil (1980) due to its applicability to analyse the real situation in the medical tourism industry. Apart from that, this section will also describe on the challenges that medical practitioners face along with the strategies that should be taken by them and the patients.

\subsection{Conflicting resource allocation between domestic and international market}

In 1980, Cavusgil developed a model that specialises in the initial involvement of internationalisation process. Cavusgil (1980) is in harmony with previous research regarding firms' initial involvement in international marketing whereby firms' internationalisation is a gradual process that occurs in incremental stage through a relatively long period. Apart from that, Cavusgil (1980) also posits that the stage approach of internationalisation begins with firms expanding their business to the surrounding environment and gradually enter relatively further markets whereby firms are expected to constantly make choices in allocating resources to meet the demands between domestic and international market. Hence, firms need to weight on the risks that home country may face as a result of their internationalisation efforts. Thus, Cavusgil (1980) contended that firms' ability to retain in the internationalisation activities rely on the management of both markets and how well obstacles are countered. Given this, medical tourism is not exempted from facing limited resources that, to a point, impinging the local patients' rights to affordable healthcare services. For instance, Selim, Noor Hazilah, and Rafikul (2017) conjectured that the medical tourism activities have resulted in Malaysian private healthcare sector increasing their expenditure to attract more foreign patients. Not only Malaysia is still behind Thailand and Singapore concerning international patient services (Selim et al., 2017), the locals are left with rising healthcare cost as hospitals have to bear for the escalating operational costs such as medical devices. Apart from that, the authors also posit that the public healthcare lags behind the private sector in terms the service quality indicating that the benefits of the medical tourism industry have not been ploughed to improve the public healthcare. Hence, the present study takes Selim et al. (2017) empirical findings as one of the bases to argue that the local healthcare needs are not adequately served for indicating that the private hospitals have not correctly allocated their resources to equally serve the local patients and medical tourist accordingly.

Moreover, medical practitioners would rather serve in other countries for higher pay due to the growth of medical tourism internationally (Ormond \& Sulianti, 2014) and serving to local patients is no more the trend of medical practitioners. This may be due to the lack of emphasis on nationality during their education and training years especially for those graduating from overseas. Private sector medical practitioners are also in the dilemma when it comes to the issue of priority of treatment as they may tend to serve (foreign patients above local patients for the higher incentives due to variation in terms of charges between the local and foreign patients. Since there is no guideline on the responsibility of the medical practitioners to give priority to local patients, medical practitioners tend to continue to give more attention to foreign patients. Furthermore, it is found that 354 cosmetic medical tourists in Korea indicated that outcome fairness is the strongest variable affecting dissatisfaction, followed by interpersonal, procedural, and informational fairness, and dissatisfaction triggers specific behaviors such as negative word of mouth, switching to other service providers and complaining (Um \& Kim, 2018). Realising the potential adverse effects to the medical practitioners and healthcare facilities, the behaviour of favouring foreign patients above the locals is sometimes portrayed by medical practitioners illustrating the unequal treatment by medical practitioners which may influence the level of satisfaction of a local patient. Indirectly, it would lead to the local patients fleeing to foreign countries for treatment.

Discussions about ethical concerns of medical tourism have also focused on potential impacts on public health in both destination and departure countries. In destination countries, medical tourism may divert resources from the public to private sector, including human health resources and public funding. Furthermore, the development of medical tourism industries may reorient the emphasis of public health in these countries on developing and providing health care which prioritises the needs of international patients over domestic health needs (Adams, Snyder, Crooks, \& Johnston, 2017). This industry may also further privatise health care in these destinations, resulting in reduced access to health care for persons unable to pay. For countries of origin for medical tourists, there is concern that resources may be diverted from public health care to treat complications obtained from treatment abroad while persons leaving the 
country may reduce the pressure for health care system reform needed to meet the health needs of the population. With this in mind, persons that are unable to travel for medical care may be unable to access needed health care through medical tourism (Adams et al., 2017).

Additionally, the Ministry of Women Family and Community Development (2016), in their study has identified relevant indicators that can provide information about the well-being of families in Malaysia. Subsequently, based on the identified indicators, a Family WellBeing Index (FWI) was developed to measure the current state of well-being of the family as well as for use in new policy formulation, planning for implementation of future research, the development of new programmes and services, and expansion of existing programmes. Accordingly, the Ministry of Women Family and Community Development (2016) posited that the Malaysian Family Wellbeing Index 2016 is showing that the wellbeing index of Malaysians is moderate. Meanwhile, the Family, Role of Religion and Spiritual Practices Domain is the highest score of 8.04 over 10. This is followed by Family and Community (7.83), Family Relationship (7.82), Family Safety (7.39), Family Health (7.38), Housing and Environment (7.28) and finally Family Economy (6.90). The imperatively poor health situation of Malaysians indicated the urgency for medical practitioners to provide equal attention between the local patients and foreign medical tourists thus signifying the gap between Cavusgil (1980)'s argument on the needs for firms to manage both markets.

The conflicting gap between the literature from Cavusgil (1980)'s "resource allocation between foreign and domestic demand" and the industry's practically low service quality of public healthcare and costly private health services to the locals rationalise the urgency for the present study. As Cavusgil (1980) conceived that the long-term success of firms' internationalisation boils down to their ability to plan and execute their marketing mix, which involves the people to serve, it therefore condones the needs for the present study to characterise the mentioned situation that concerns both the local and foreign patients. This is so that the industry is able to return the benefits of medical tourism to the local healthcare sector.

\subsection{Challenges for Medical Practitioners}

The Star Online posited that many Malaysians are going abroad to seek medical treatments despite Malaysia's distinguished awards and recognition in medical tourism (Chin, 2016). Despite cheaper and equally good care here, Malaysians tend to go elsewhere for treatment if they do not receive enough information about the available services locally. It is an irony that despite being a medical tourism hub, the Malaysians are opting for overseas treatment due to the restricted advertisements allowed on healthcare services (Chin, 2016).

'Advertisement' under the Medicines (Advertisement and Sale) Act 1956 comprises of any circular, notice, report, commentary, wrapper, label, pamphlet inclusive of documents and announcements. Accordingly, among the restricted activities are doctor publicising his place of practice, before-and-after pictures of patients(Chin, 2016). Unlike Malaysia, countries like Thailand and Singapore allow the medical industry to publish patient testimonials which are easily accessible online. This also means that Malaysians have access to information about treatments abroad, but their knowledge is scarce about what is available at home (Chin, 2016). Conventionally, medical professionals are discouraged from advertising due to several reasons such as to avoid misleading the public and to keep away from raising false hopes of a cure. But in view of the changing trends, the Malaysian Medical Council (MMC) is reviewing and revising the code of practice "in the interest of the profession and the public", stressing that patient safety and interest remain of utmost importance(Chin, 2016).

Although the healthcare professional upholds honesty, practitioners believed that that should not negate the idea of telling the public about the latest available advancements to repair heart valves or even reverse the effects of acute stroke (Chin, 2016) because providing information is not the same as soliciting business. Furthermore, registered specialists should at least be allowed to provide factual information about their experience and background. Nevertheless, the regulations are strict that individual doctors are not allowed to advertise in any form (Chin, 2016). Although the advertising regulations have been lenient over time, the present state is still not at a level playing field as standalone specialist clinics are not allowed to advertise freely. Moreover, the primary obstacle to the development of a substantial medical market is also due to the transparency in the MMC on charging against doctors and individual clinics but leaving many loopholes for the 'big players' and other healthcare services to advertise (Chin, 2016). For instance, although a doctor and a beautician may be using the same treatment machine yet only the latter can shout about it. In view of that, clarification is needed to differentiate between individual doctors' advertisement and the endorsement of a healthy facility as a business organisation.

Hence, it is seen that from the medical practitioners' point of view, the existing rules and regulations are hindering them from providing services to the locals. Although local patients have the tendency to seek treatment at hospitals or physicians that they are familiar with, the private healthcare service providers posit that advertisement on their extant facilities, expertise and quality should be brought forward. Further, the hindrance of such activity posits negative effects towards the local patients in terms of not knowing the availability of such services, as well as to the service providers who would have to advertise to foreign patients in order to utilise the available capacity. Hence, the next section will delineate on the strategies that should be taken by doctors, patients and the regulatory body.

\subsection{The Way Forward: Practitioners' and Patients' Roles and Responsibilities}

Responsible tourism practices would escalate the quality of life of the service providers, tourists and the locals (Ginting, Rahman, \& Nasution, 2017; Hanafiah, Azman, Jamaluddin, \& Aminuddin, 2016). Therefore, there is a strong need for service providers as well as both the local and foreign patients to play their roles in correcting the situation. While attending to the patients needs revolves around the interaction between the medical practitioners and patients, it is essential to note that health studies have, over the last two decades, reported that poor physician communication would lead to hesitation and refutation, apprehension and depression and problematic psychological adjustment to cancer patients (Srivastava, Shukla, Kaushik, \& Tewari, 2017) and to all patients as a whole. This communication consists of i) Instrumental Behaviour which revolves around asking and giving information to treat the patients' illness; 
ii) Socio-Emotional Behaviour that aims at making patients feel more comfortable through friendliness, empathy and reassurance; and iii) Affective Behaviour which is formed through non-verbal behaviour such as appropriate voice tone, eye contact, time spent on consultation and sits down while consulting patients. These communication behaviours would result in less distressed, more satisfied and psychologically better-adjusted patients (Srivastava et al., 2017).Doctors should avoid disturbances such as making phone calls and doing research on the internet or leaflets as means to suggest other sources of information as patients consider direct conversation more than using filters to provide consultation.

Apart from that, medical service providers and practitioners should ensure conducive environment at the hospital because it would affect patients satisfaction level (Ghazali \& Abbas, 2012). Such environment can be in the form of clean facilities, aesthetic elements in the building and courtyard (Almhafdy, Ibrahim, Ahmad, \& Yahya, 2013) and appropriate management strategy (Rani, Baharum, Akbar, \& Nawawi, 2015). Moreover, reciprocal engagement and commitment between patients and doctors during consultation should also be taken serious attention. Patients are also expected to respond to doctors accordingly during consultation such as providing clear information of their symptoms and descriptively explain their situation rather than jumping into medication without allowing the doctors to examine first. Medication and physical therapies should be continued at home to ensure progressive health conditions at posttreatment. Moreover, the local patients are also responsible in adhering to the follow-up sessions to ensure continuity of treatment. Failing to abide by the scheduled sessions would not only adversely affect their health, but also their communication with the medical practitioners. Due to this, local patients must not be upset should they observe that priorities are given to foreign patients in private healthcare facilities because of their timely arrival and adherence to the treatment schedule.

In terms of regulation, it is seen that the Malaysian government plans to provide the Flagship Medical Tourism Hospital Programme to private hospitals as encouragement to attract medical tourists, along with several other tax deduction for marketing and development purposes (Ministry of Finance, 2017). Nevertheless, while the endorsement of hospitals' latest available facilities and machineries are hindered under the Medicines (Advertisement and Sale) Act 1956, it calls for the relevant policymakers to realign the local patients' health policy. Accordingly, the present article refers to the discussion from Frenk (1994) and later advanced by Lunt et al. (2011) that delineates three aspects of healthcare services in light of prioritising the locals over foreign patients. The first aspect that should be taken into consideration is 'regulation and finance' in order to ensure appropriate income into the country. This aspect calls for technology transfer, skill enhancement and foreign income into the country. It also reflects the needs for public hospitals in Malaysia to improve on its space quality care which includes technicality, functionality and aesthetic (Samah, Ibrahim, \& Amir, 2013) that offers a healing environment to patients and medical practitioners (Kamali \& Abbas, 2012).

The second aspect that policymakers need to look into 'system priorities' to ensure allocation efficiency (Frenk, 1994; Lunt et al., 2011). It also means that resources and capacities should not be taken away from the local patients. This is so because the available capacity is already low in many hospitals (Setyowati, Harani, \& Falah, 2013). Considering that the existing public hospitals have long waiting list and that the private healthcare are not allowed to promote their services, this would mean that Malaysians are in need of more public hospitals and physicians to serve for the local demand of healthcare. As patients and their family's hopes on the service providers for cure are increasingly high (Hashim \& Hussin, 2012), it is of the regulatory body's responsibility to ensure ample healthcare services are available for the locals. Apart from that, it is also important that the local patients in city, sub-urban and let alone rural areas have their safety ensured throughout the treatment as patients' safety in healthcare services (Othman, Jaafar, Harun, \& Ibrahim, 2015) is the utmost importance for every service provider. As medical practitioners' needs are also important to cater for (Kamali \& Abbas, 2012), having more healthcare facilities available for the locals would also create more employment opportunities them thus reducing the issue of brain drain in the healthcare sector.

The final aspect of the health policy is 'management of services and treatments' (Frenk, 1994; Lunt et al., 2011) that calls for medical practitioners to have proper record of their patients' health and treatment history. This is to avoid misconduct deliberately or negligently. Such practice does not only result in improved service quality for the local patients but also as an added value to the overall service quality of Malaysian healthcare system which stands as a strong point for the development of tourism industry as a whole (Ismail, Hanafiah, Aminuddin, \& Mustafa, 2016). Easy access for the records would result in seamless healthcare experience for the patients while having improved care delivery would help in improving the quality of life of the family members (Ghani, Ainuddin, \& Dahlan, 2016). This can come through being more empathic to the patients' problems, improving their sense of becoming a better person and strengthening their family relationships.

\subsection{Conclusion}

While the demand for ample, efficient and productive improvements for healthcare facilities is high (Ngowtanasuwan \& Ruengtam, 2013), it is important to note that the local patients in Malaysia are receiving relatively low quality of healthcare as opposed to the medical tourists. The internationalisation model by Cavusgil (1980) has revealed a practical gap in the industry specifically in terms of the conflicting resource allocation between the medical tourists and foreign patients. This comes in the form of expensive healthcare cost at private healthcare facilities, poor accessibility, unawareness of the available treatment and long waiting time at public hospital. In view of this, the present article suggested several solutions to improve the situation that involves the patients, service providers and medical practitioners, as well as the regulatory body. As hospitals offer a wide opportunity for research (Lawson, 2013) future research is recommended to embark on gaining insights on service quality at private healthcare centres to capture their experience while undergoing treatments. This may be endeavoured through qualitative case studies with interviews on the patients and service providers without being confined with preconceived variables that quantitative research is bounded by. This is to see that if unhealthy behaviour by medical practitioners actually occurs towards the locals relative to the medical tourists. 


\subsection{Acknowledgement}

The authors would like to thank the Ministry of Higher Education Malaysia for the financial support through the Fundamental Research Grant Scheme (FRGS), File No: 600-RMI/FRGS 5/3 (36/2015) and the Research Management Centre, Institute of Research Management \& Innovation (IRMI) Universiti Teknologi MARA, Shah Alam for managing the fund.

\subsection{References}

Adams, K., Snyder, J., Crooks, V. A., \& Johnston, R. (2017). Developing an informational tool for ethical engagement in medical tourism. Philosophy, Ethics, and Humanities in Medicine, 12(1), 4. doi:10.1186/s13010-017-0045-9

Almhafdy, A., Ibrahim, N., Ahmad, S. S., \& Yahya, J. (2013). Analysis of the Courtyard Functions and its Design Variants in the Malaysian Hospitals. Procedia - Social and Behavioral Sciences, 105, 171-182. doi:https://doi.org/10.1016/j.sbspro.2013.11.018

Azmi, E., \& Ismail, M. Z. (2016). Cultural Heritage Tourism: Kapitan Keling Mosque as a Focal Point \& Symbolic Identity for Indian Muslim in Penang. Procedia - Social and Behavioral Sciences, 222, 528-538. doi:https://doi.org/10.1016/j.sbspro.2016.05.211

Cavusgil, S. (1980). On the internationalization process of firms. European Research, 8, 273-281.

Chen, Y. Y., \& Flood, C. M. (2013). Medical tourism's impact on health care equity and access in low- and middle-income countries: making the case for regulation. Journal of Law, Medicine and Ethics, 41(1), 286-300.

Chin, C. (2016). Keeping Our Patients. The Star Online. Retrieved from https://www.thestar.com.my/news/nation/2016/01/10/keeping-our-patients-malaysia-is-becominga-world-medical-hub-yet-malaysians-are-seeking-treatment-a/

Fachrudin, H. T., \& Lubis, M. D. (2016). Planning for Riverside Area as Water Tourism Destination to Improve Quality of Life Local Residents, Case Study: Batuan Sikambing River, Medan, Indonesia. Procedia - Social and Behavioral Sciences, 234, 434-441. doi:https://doi.org/10.1016/j.sbspro.2016.10.261

Frenk, J. (1994). Dimensions of health system reform. Health Policy, 27(1), 19-34.

Ghani, S. N. A., Ainuddin, H. A., \& Dahlan, A. (2016). Quality of Life Amongst Family Caregivers of Older Persons with Terminal Illnesses. Procedia - Social and Behavioral Sciences, 234, 135-143. doi:https://doi.org/10.1016/j.sbspro.2016.10.228

Ghazali, R., \& Abbas, M. Y. (2012). Newly Built Public Paediatric Wards Increase Length of Stay (LOS)? In M. Y. Abbas, A. F. I. Bajunid, \& N. F. N. Azhari (Eds.), AceBs 2012 Bangkok (Vol. 50, pp. 623-632). Amsterdam: Elsevier Science Bv.

Ginting, N., Rahman, N. V., \& Nasution, A. D. (2017). Increasing Tourism in Karo District, Indonesia Based on Place Identity. Environment-Behaviour Proceedings Journal, 2(5), 177-184.

Gola, S. (2015). International trade and health equity: Have benefits of medical tourism 'Trickled Down'to India's poor. International Trade \& Health Equity: Medical Tourism, 1, 1-20.

Hanafiah, M. H., Azman, I., Jamaluddin, M. R., \& Aminuddin, N. (2016). Responsible Tourism Practices and Quality of Life: Perspective of Langkawi Island communities. In M. Y. Abbas, A. F. I. Bajunid, \& S. Thani (Eds.), Asean-Turkey Asli Qol2015: Aicqol2015 (Vol. 222, pp. 406-413).

Hashim, F., \& Hussin, R. (2012). Family Needs of Patient Admitted to Intensive Care Unit in a Public Hospital. In M. Y. Abbas, A. F. I. Bajunid, \& N. F. N. Azhari (Eds.), Asean Conference on Environment-Behaviour Studies (Vol. 36, pp. 103-111). Amsterdam: Elsevier Science Bv.

Helble, M. (2011). The movement of patients across borders: challenges and opportunities for public health. Bulletin of the World Health Organization, 89(1)(Past Issues), 68-72.

Ismail, M. N. I., Hanafiah, M. H., Aminuddin, N., \& Mustafa, N. (2016). Community-based Homestay Service Quality, Visitor Satisfaction, and Behavioral Intention. Procedia - Social and Behavioral Sciences, 222, 398-405. doi:https://doi.org/10.1016/j.sbspro.2016.05.192

Kamali, N. J., \& Abbas, M. Y. (2012). Healing Environment: Enhancing Nurses' Performance through Proper Lighting Design. Procedia - Social and Behavioral Sciences, 35, 205-212. doi:https://doi.org/10.1016/j.sbspro.2012.02.080

Lawson, B. (2013). Design and the Evidence. Procedia - Social and Behavioral Sciences, 105, 30-37. doi:https://doi.org/10.1016/j.sbspro.2013.11.004

Lunt, N., Smith, R., Exworthy, M., Green, S. T., Horsfall, D., \& Mannion, R. (2011). Medical tourism: treatments, markets and health system implications: a scoping review. Paris: Organisation for Economic Co-operation and Development.

Ministry of Finance. (2017). 2018 Budget. Kuala Lumpur: Percetakan Nasional Malaysia Berhad.

Ministry of Women Family and Community Development. (2016). Family Well-being Index 2016.

National Transformation Program. (2017). Economic Transformation Program Annual Report 2016. Retrieved from

Ngowtanasuwan, G., \& Ruengtam, P. (2013). Applied Simulation Model for Design of Improving Medical Record Area in Out-patient Department (OPD) of a Governmental Hospital. Procedia - Social and Behavioral Sciences, 101, 147-158. doi:https://doi.org/10.1016/j.sbspro.2013.07.188

Nisha. (2017). 9 Things We Learned from InsigHT2017: A Convergence of Voices on Medical Travel. Retrieved from https://www.mhtc.org.my/9-things-we-learned-frominsight2017-a-convergence-of-voices-on-medical-travel/ 
Ormond, M., \& Sulianti, D. (2014). More than medical tourism: lessons from Indonesia and Malaysia on South-South intra-regional medical travel. Current Issues in Tourism, 20(1), 94-110. doi:10.1080/13683500.2014.937324

Othman, N. L., Jaafar, M., Harun, W. M. W., \& Ibrahim, F. (2015). A Case Study on Moisture Problems and Building Defects. In M. Y. Abbas (Ed.), Asian Conference on Environment-Behaviour Studies (Vol. 170, pp. 27-36).

Rani, N. A. A., Baharum, M. R., Akbar, A. R. N., \& Nawawi, A. H. (2015). Perception of Maintenance Management Strategy on Healthcare Facilities. Procedia - Social and Behavioral Sciences, 170, 272-281. doi:https://doi.org/10.1016/j.sbspro.2015.01.037

Rasiah, R., Wan Abdullah, N. R., \& Tumin, M. (2011). Markets and Healthcare Services in Malaysia Critical Issues. International Journal of Instituttions and Economies, 3(3), 467-486.

Razak, M. N. (2015). Eleventh Malaysia Plan. Putrajaya: Prime Minister Office.

Samah, Z. A., Ibrahim, N., \& Amir, J. S. (2013). Translating Quality Care Factors to Quality Space: Design Criteria for Outpatient Facility. Procedia - Social and Behavioral Sciences, 105, 265-272. doi:https://doi.org/10.1016/j.sbspro.2013.11.028

Selim, A., Noor Hazilah, A. M., \& Rafikul, I. (2017). Measuring quality performance between public and private hospitals in Malaysia. International Journal of Quality and Service Sciences, 9(2), 218-228. doi:10.1108/IJQSS-02-2017-0015

Setyowati, E., Harani, A. R., \& Falah, Y. N. (2013). Green Building Design Concepts of Healthcare Facilities on the Orthopedic Hospital in the Tropics. In M. Y. Abbas (Ed.), Amer (Vol. 101, pp. 189-199). Amsterdam: Elsevier Science Bv.

Srivastava, J., Shukla, H. S., Kaushik, S. S., \& Tewari, M. (2017). Interaction with Cancer Patients: Psychological Impact of Doctors' Communication Behaviour.

Um, K.-H., \& Kim, S.-M. (2018). Application of Fairness Theory to Medical Tourists' Dissatisfaction and Complaint Behaviors: The Moderating Role of Patient Participation in Medical Tourism. Journal of Social Service Research, 44(2), 191-208.

World Health Organisation. (1946). Constitution of the World Health Organization: Principles. About WHO. Retrieved from http://www.who.int/about/mission/en/ 